\title{
Gravity data interpretation using the particle swarm optimisation method with application to mineral exploration
}

\author{
Khalid S Essa ${ }^{1, *}$ (๑) and Marc Munschy ${ }^{2}$ \\ ${ }^{1}$ Department of Geophysics, Cairo University, Giza, Egypt. \\ ${ }^{2}$ Institut de Physique du Globe de Strasbourg, EOST, CNRS, University of Strasbourg, Strasbourg, France. \\ ${ }^{*}$ Corresponding author. e-mail: khalid_sa_essa@yahoo.com
}

MS received 4 September 2018; revised 25 November 2018; accepted 28 November 2018;

published online 8 May 2019

This paper describes a new method based on the particle swarm optimisation (PSO) technique for interpreting the second moving average (SMA) residual gravity anomalies. The SMA anomalies are deduced from the measured gravity data to eradicate the regional anomaly by utilising filters of consecutive window lengths ( $s$-value). The buried structural parameters are the amplitude factor $(A)$, depth $(z)$, location $(d)$ and shape $(q)$ that are estimated from the PSO method. The discrepancy between the measured and the predictable gravity anomaly is estimated by the root mean square error. The PSO method is applied to two different theoretical and three real data sets from Cuba, Canada and India. The model parameters inferred from the method developed here are compared with the available geological and geophysical information.

Keywords. Particle swarm optimisation; second moving average; discrepancy; depth; mineral exploration.

\section{Introduction}

Potential methods have diverse applications in exploration geophysics (Mehanee 2015; Biswas 2017; Essa et al. 2018; Kawada and Kasaya 2018). Gravity method, in particular, has extensive applications in hydrocarbon, mineral, caves, geothermal and archaeological investigations (Hinze et al. 2013; Nishijma and Naritomi 2017). The aim of gravity data elucidation is to assess the body parameters of the buried structures, e.g., the amplitude, depth, location and shape (Essa 2014; Biswas 2015). The gravity data elucidation can suffer from limitations including non-uniqueness and ill-posedness (Mehanee 2014; Mehanee and Essa 2015). The use of simple geometrical structures in gravity inversion helps overcoming these limitations, gives an optimal fit for the buried structures and plays a vigorous role in solving many investigation issues (Essa 2011; Asfahani and Tlas 2015).

Numerous conventional and non-conventional methods have been recognised to interpret gravity data such as characteristic points and distances, monograms and standardised curve-matching (Rao et al. 1986; Essa 2007a) transformations (Babu et al. 1991; Sundararajan and Rama Brahmam 1998; Al-Garni 2008), linear and nonlinear least squares (Gupta 1983; Essa 2011, 2012; Abdelrahman and Essa 2015), fair functions (Asfahani and Tlas 2012), Euler and Werner deconvolution (Kilty 1983; Stavrev 1997), moving average (Abdelrahman et al. 2003, 2006; Abdelrahman and Essa 2013; Abdelrahman et al. 2013; Essa 2013), 
two- and three-dimensional (2D and 3D) modelling and inversion (Chai and Hinze 1988; Zhang et al. 2001), derivative-based techniques (Ekinci et al. 2013; Ekinci and Yiğitbaş 2015), particle swarm optimisation (Singh and Biswas 2016), very fast simulated annealing (Biswas 2016), genetic algorithm (Amjadi and Naji 2013), forced neural network (Osman et al. 2006) and differential evolution algorithm (Ekinci et al. 2016). However, some of these methods necessitate virtuous primary parameters, which depend on the geological information, using a few data points and distances and require more time. In addition, the accuracy of the expected model parameters can rely upon the precision of the residual gravity anomaly isolated from the measured data.

This paper developed a new approach depending on the PSO technique for interpreting the second

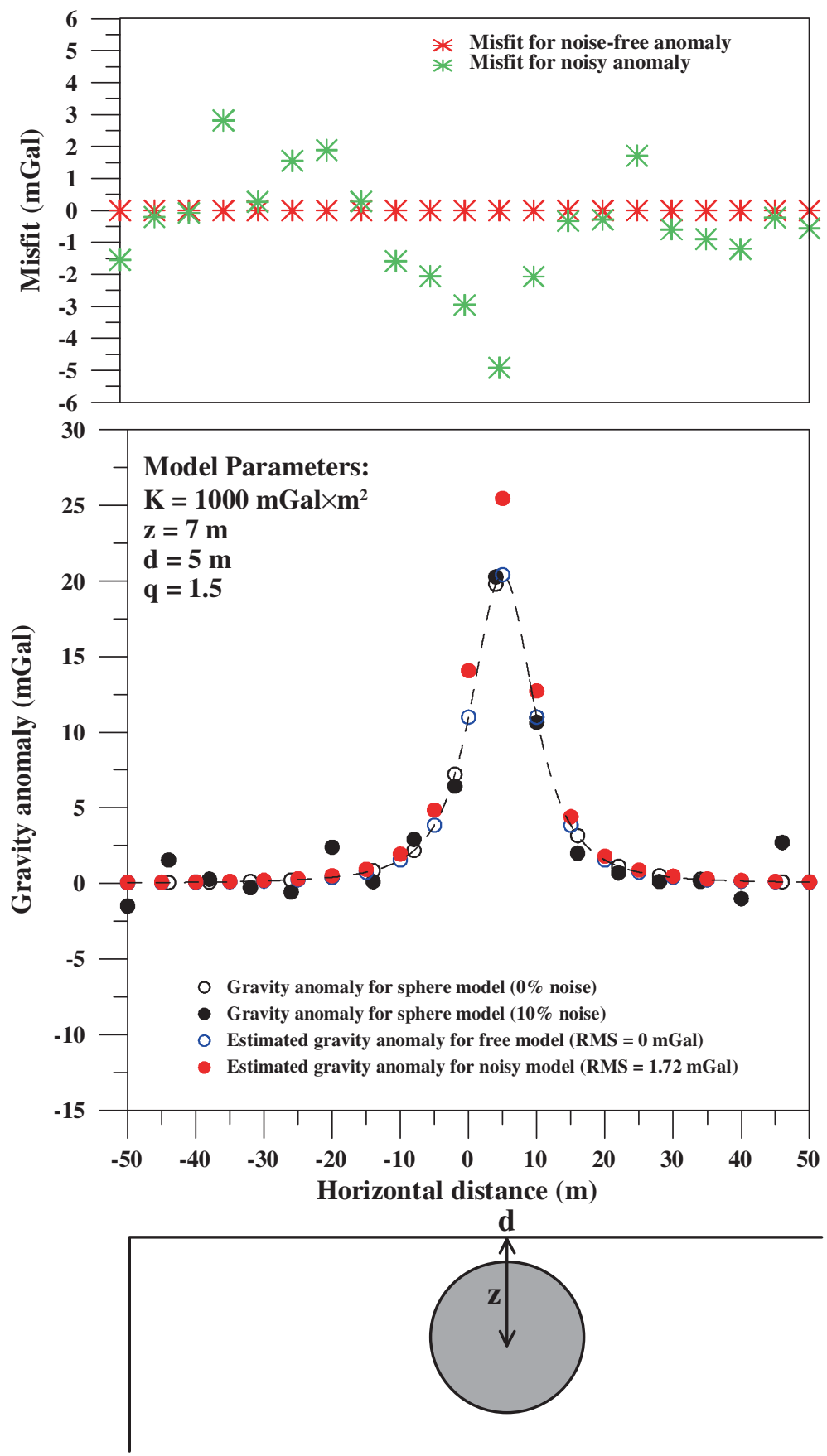

Figure 1. Top panel represents the discrepancy between the observed and the predicted anomaly. The middle panel is a theoretical sphere model $\left(A=1000 \mathrm{mGal} \times \mathrm{m}^{2}, z=7 \mathrm{~m}, d=5, q=1.5\right.$ and profile length $\left.=100 \mathrm{~m}\right)$ without and with $10 \%$ random noise. The lower panel is a geological sketch of the buried model. 
moving average (SMA) residual gravity anomalies. This technique has the capability to appraise the exact parameters for the buried structures (amplitude factor $(A)$, depth $(z)$, the location $(d)$ and the shape $(q)$ ) and benefit in eliminating the regional anomaly. The accuracy of this method was tested on two different theoretical examples and examined on three real data for mineral exploration from Cuba, Canada and India.

\section{Methodology}

Pawlowski (1994) recognised that the potential field anomaly consists of the impact of the shallow and deep geological structures. This anomaly can be expressed as

$$
g\left(x_{j}\right)=g_{\mathrm{res}}\left(x_{j}\right)+g_{\mathrm{reg}}\left(x_{j}\right),
$$

where $g\left(x_{j}\right)$ is the measured gravity field at an $x$-coordinate, $g_{\text {res }}$ represents the gravity anomaly of shallow structures (residual anomaly) and $g_{\text {reg }}$ is the gravity anomaly for the deeper structures (regional anomaly). Elimination of the regional anomaly is one of the most significant problems in potential field data interpretation. Therefore, the SMA method has been utilised to remove the regional anomaly from the measured data.

\subsection{SMA method}

The gravity anomaly $(g)$ for a simple geometrical source at $x_{i}$ (Essa 2014; Biswas 2015) is given by

$g\left(x_{j}\right)=A \frac{z^{m}}{\left[\left(x_{j}-d\right)^{2}+z^{2}\right]^{q}}, j=0,1,2,3, \ldots, N$,

where $A$ is the amplitude factor $\left(\mathrm{mGal} \times \mathrm{m}^{2 q-m}\right)$, $z$ is the depth $(\mathrm{m}), d$ is the location $(\mathrm{m}), m$ and $q$ are the constant and shape parameter that equals 1.5, 1.0 and 0.5 for a spherical body, a horizontal cylinder body and a semi-infinite vertical cylinder body, respectively (Essa 2007b).

According to Griffin (1949) who designates the first moving-average residual anomaly $\left(R_{1}\right)$ as

$R_{1}\left(x_{j}, z, s\right)=\left[\frac{2 g\left(x_{j}\right)-g\left(x_{j}+s\right)-g\left(x_{j}-s\right)}{2}\right]$.

So, the SMA residual gravity anomaly, $R_{2}\left(x_{j}, z, s\right)$, is well characterised as

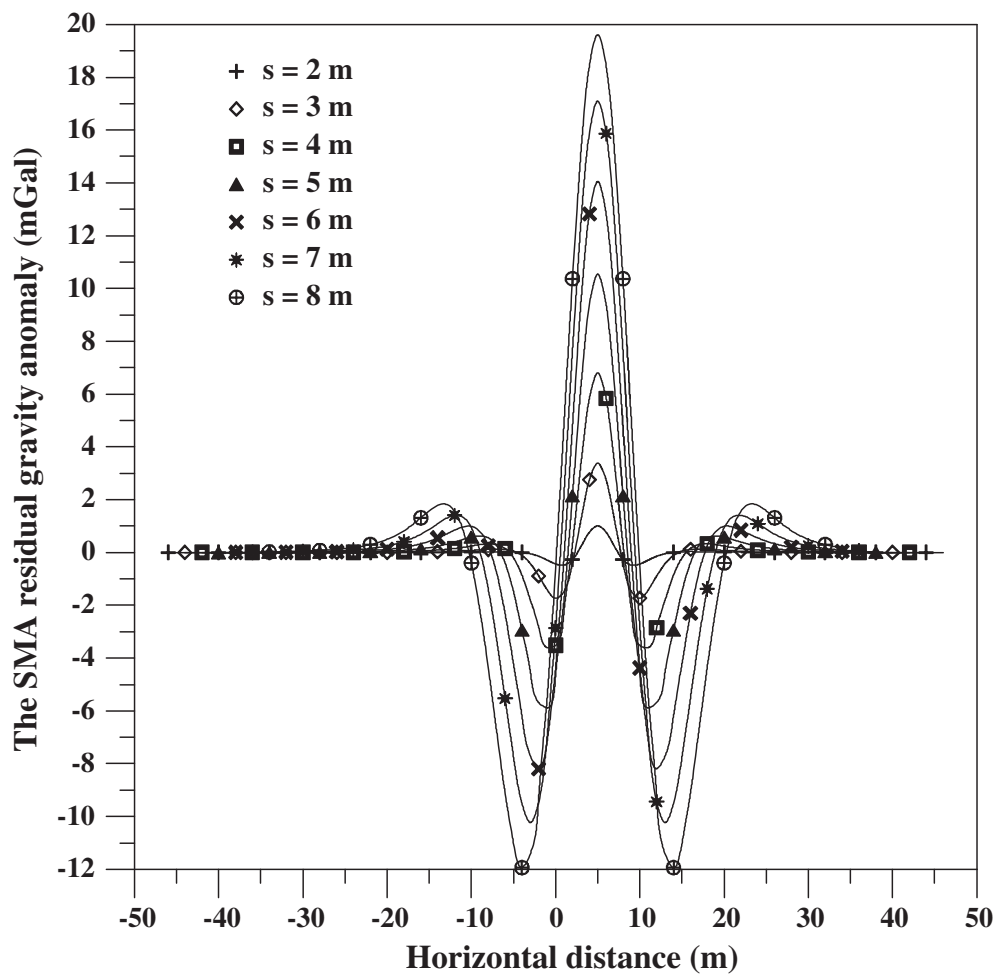

Figure 2. SMA residual gravity anomalies for figure 1 in the case of noise free data. 
Table 1. Numerical results for the PSO-method application on the SMA residual gravity data using several s-values for a sphere model $\left(A=1000 \mathrm{mGal} \times \mathrm{m}^{2}, z=7 \mathrm{~m}, \mathrm{~d}=5, q=1.5\right.$ and profile length $\left.=100 \mathrm{~m}\right)$ without and with $10 \%$ random noise.

\begin{tabular}{|c|c|c|c|c|c|c|c|c|c|c|c|}
\hline \multirow[b]{2}{*}{ Parameters } & \multirow[b]{2}{*}{$\begin{array}{c}\text { Used } \\
\text { ranges }\end{array}$} & \multicolumn{10}{|c|}{ Using the PSO-inversion for the SMA anomalies } \\
\hline & & $\begin{array}{l}s= \\
2 \mathrm{~m}\end{array}$ & $\begin{array}{l}s= \\
3 \mathrm{~m}\end{array}$ & $\begin{array}{l}s= \\
4 \mathrm{~m}\end{array}$ & $\begin{array}{l}s= \\
5 \mathrm{~m}\end{array}$ & $\begin{array}{l}s= \\
6 \mathrm{~m}\end{array}$ & $\begin{array}{l}s= \\
7 \mathrm{~m}\end{array}$ & $\begin{array}{l}s= \\
8 \mathrm{~m}\end{array}$ & $\phi$-value & $\begin{array}{c}E \text {-value } \\
(\%)\end{array}$ & $\begin{array}{l}\text { RMSE } \\
\text { (mGal) }\end{array}$ \\
\hline \multicolumn{12}{|l|}{ Without noise } \\
\hline$A\left(\mathrm{mGal} \times \mathrm{m}^{2}\right)$ & $500-2000$ & 1000 & 1000 & 1000 & 1000 & 1000 & 1000 & 1000 & 1000 & 0 & 0 \\
\hline$z(\mathrm{~m})$ & $1-10$ & 7 & 7 & 7 & 7 & 7 & 7 & 7 & 7 & 0 & \\
\hline$d(\mathrm{~m})$ & -10 to 10 & 5 & 5 & 5 & 5 & 5 & 5 & 5 & 5 & 0 & \\
\hline$q$ (dimensionless) & $0.1-1.7$ & 1.5 & 1.5 & 1.5 & 1.5 & 1.5 & 1.5 & 1.5 & 1.5 & 0 & \\
\hline \multicolumn{12}{|l|}{ With $10 \%$ noise } \\
\hline$A\left(\mathrm{mGal} \times \mathrm{m}^{2}\right)$ & $500-2000$ & 975.32 & 980.41 & 983.17 & 988.63 & 993.80 & 990.74 & 991.20 & 986.18 & 1.38 & 1.72 \\
\hline$z(\mathrm{~m})$ & $1-10$ & 6.38 & 6.57 & 6.63 & 6.78 & 6.71 & 6.89 & 6.95 & 6.71 & 4.14 & \\
\hline$d(\mathrm{~m})$ & -10 to 10 & 4.63 & 4.66 & 4.72 & 4.76 & 4.75 & 4.88 & 4.95 & 4.76 & 4.41 & \\
\hline$q$ (dimensionless) & $0.1-1.7$ & 1.42 & 1.45 & 1.45 & 1.48 & 1.47 & 1.49 & 1.48 & 1.46 & 2.48 & \\
\hline
\end{tabular}

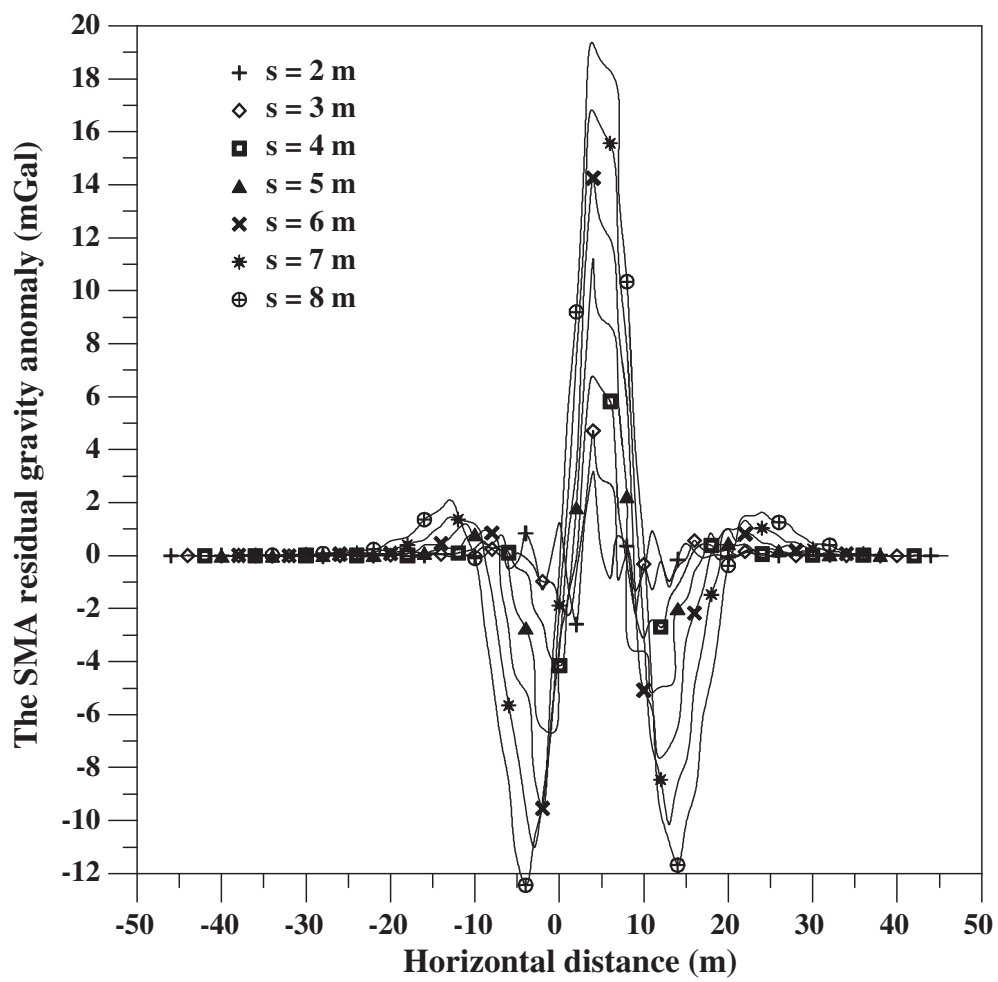

Figure 3. SMA residual gravity anomalies for figure 1 in the case of $10 \%$ noise.

$$
R_{2}\left(x_{j}, z, s\right)=\frac{6 g\left(x_{j}\right)-4 g\left(x_{j}+s\right)-4 g\left(x_{j}-s\right)+g\left(x_{j}+2 s\right)+g\left(x_{j}-s\right)}{4} .
$$

Hence, using equation (2) in equation (4), we get

$$
\begin{aligned}
R_{2}\left(x_{j}, z, s\right)= & \frac{A z^{m}}{4}\left\{\frac{6}{\left[\left(x_{j}-d\right)^{2}+z^{2}\right]^{q}}-\frac{4}{\left[\left(x_{j}-d+s\right)^{2}+z^{2}\right]^{q}}\right. \\
& \left.-\frac{4}{\left[\left(x_{j}-d-s\right)^{2}+z^{2}\right]^{q}}+\frac{1}{\left[\left(x_{j}-d+2 s\right)^{2}+z^{2}\right]^{q}}+\frac{1}{\left[\left(x_{j}-d-2 s\right)^{2}+z^{2}\right]^{q}}\right\} .
\end{aligned}
$$




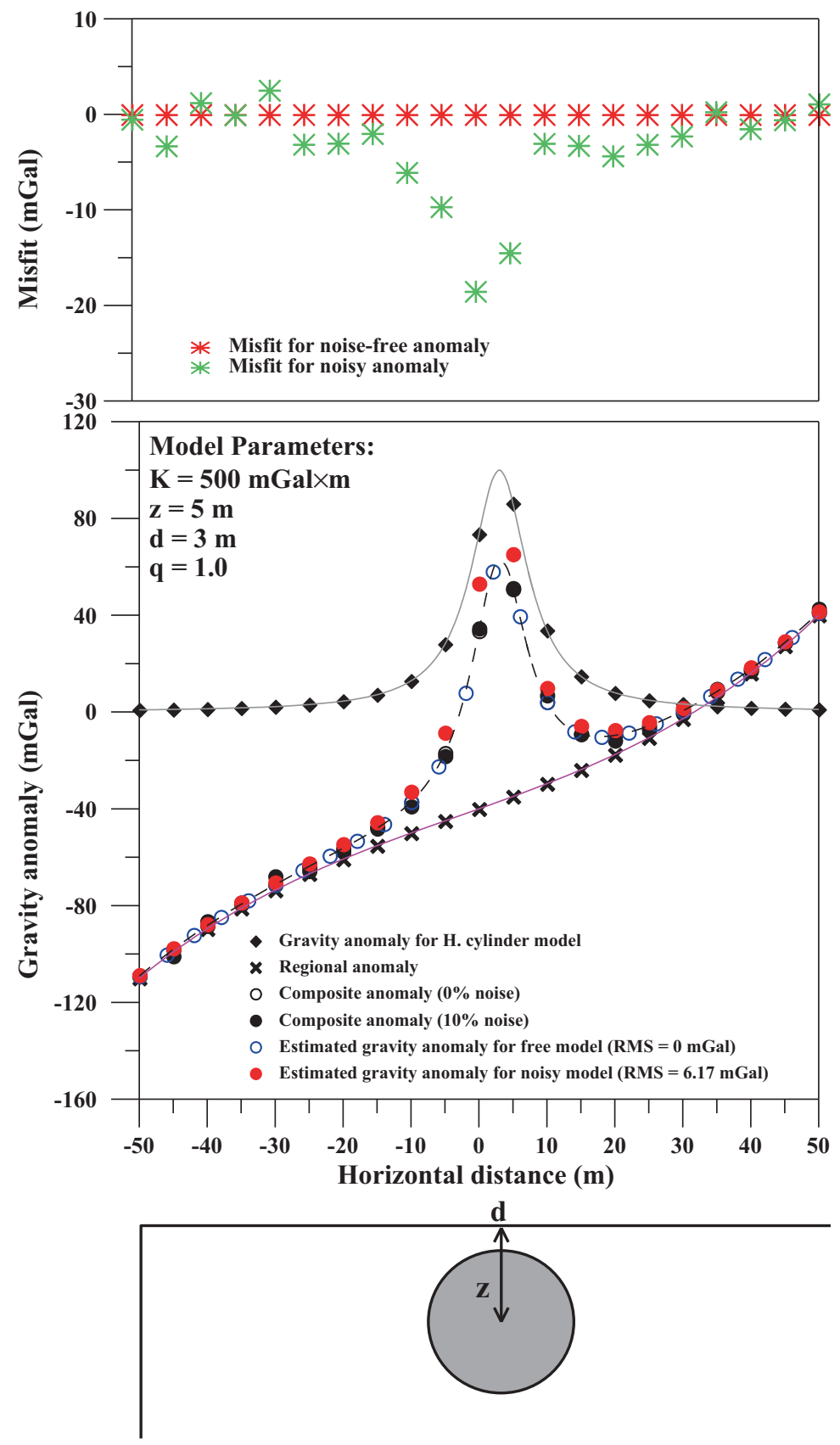

Figure 4. Top panel represents the discrepancy between the observed and the predicted anomaly. The middle panel is a theoretical horizontal cylinder model $(A=500 \mathrm{mGal} \times \mathrm{m}, z=5 \mathrm{~m}, d=3, q=1.0$ and profile length $=100 \mathrm{~m})$ and a thirdorder regional background without and with $10 \%$ random noise. The lower panel is a geological sketch of the buried model.

At the end, equation (5) is utilised to gauge the structural parameters $(A, z, d$ and $q$ ) utilising one of the stochastic advanced computation techniques, the so-called PSO method, which is efficient in resolving problematic difficulties steadily and accurately.

\subsection{PSO method}

Eberhart and Kennedy (1995) introduced the PSO method. The PSO method has many varied applications, for example, geotechnical engineering (Hajihassani et al. 2018), crystal structure predication (Wang et al. 2010), electromagnetic (Santilano et al. 2018), solar energy (Jordehi 2018), engineering design problems (He and Wang 2007) and geophysics problems (Singh and Biswas 2016; Essa and Elhussein 2018a,b; Luu et al. 2018). The PSO method is stochastic in nature and exhilarated by the common routine trip of birds looking for nourishments. The birds are the models. The independent model has a location 


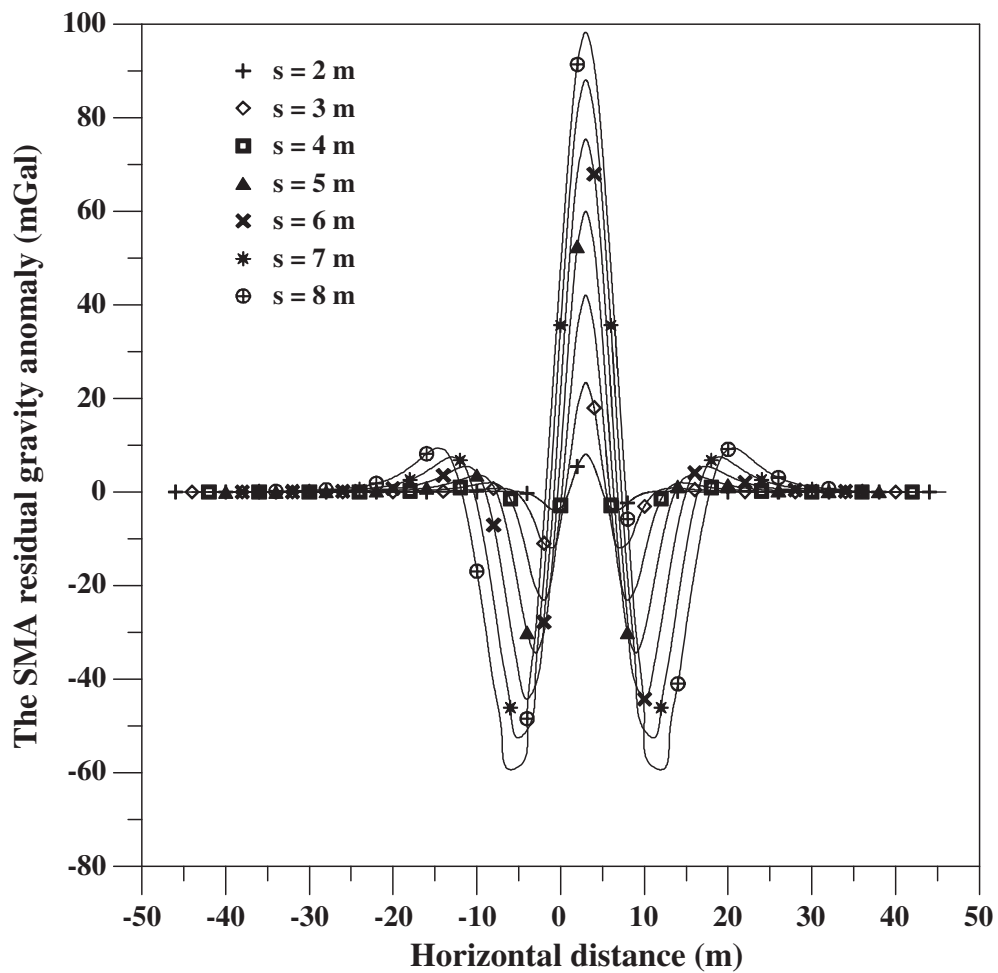

Figure 5. SMA residual gravity anomalies for figure 4 in the case of noise-free data.

Table 2. Numerical results for the PSO-method application on the SMA residual gravity data using several s-values for a horizontal cylinder model $(A=500 \mathrm{mGal} \times \mathrm{m}, z=5 \mathrm{~m}, d=3, q=1.0$ and profile length $=100 \mathrm{~m})$ and added a third-order regional background without and with $10 \%$ random noise.

\begin{tabular}{|c|c|c|c|c|c|c|c|c|c|c|c|}
\hline \multirow[b]{2}{*}{ Parameters } & \multirow[b]{2}{*}{$\begin{array}{c}\text { Used } \\
\text { ranges }\end{array}$} & \multicolumn{10}{|c|}{ Using the PSO-inversion for the SMA anomalies } \\
\hline & & $\begin{array}{l}s= \\
2 \mathrm{~m}\end{array}$ & $\begin{array}{l}s= \\
3 \mathrm{~m}\end{array}$ & $\begin{array}{l}s= \\
4 \mathrm{~m}\end{array}$ & $\begin{array}{l}s= \\
5 \mathrm{~m}\end{array}$ & $\begin{array}{l}s= \\
6 \mathrm{~m}\end{array}$ & $\begin{array}{l}s= \\
7 \mathrm{~m}\end{array}$ & $\begin{array}{l}s= \\
8 \mathrm{~m}\end{array}$ & $\phi$-value & $\begin{array}{c}E \text {-value } \\
(\%)\end{array}$ & $\begin{array}{l}\text { RMSE } \\
\text { (mGal) }\end{array}$ \\
\hline \multicolumn{12}{|l|}{ Without noise } \\
\hline$A(\mathrm{mGal} \times \mathrm{m})$ & $100-1000$ & 500 & 500 & 500 & 500 & 500 & 500 & 500 & 500 & 0 & 0 \\
\hline$z(\mathrm{~m})$ & $1-10$ & 5 & 5 & 5 & 5 & 5 & 5 & 5 & 5 & 0 & \\
\hline$d(\mathrm{~m})$ & -10 to 10 & 3 & 3 & 3 & 3 & 3 & 3 & 3 & 3 & 0 & \\
\hline$q$ (dimensionless) & $0.1-1.5$ & 1.0 & 1.0 & 1.0 & 1.0 & 1.0 & 1.0 & 1.0 & 1.0 & 0 & \\
\hline \multicolumn{12}{|l|}{ With $10 \%$ noise } \\
\hline$A(\mathrm{mGal} \times \mathrm{m})$ & $100-1000$ & 472.45 & 477.12 & 482.87 & 485.63 & 482.95 & 486.41 & 488.77 & 482.31 & 3.54 & 6.17 \\
\hline$z(\mathrm{~m})$ & $1-10$ & 4.72 & 4.75 & 4.79 & 4.85 & 4.81 & 4.86 & 4.89 & 4.81 & 3.80 & \\
\hline$d(\mathrm{~m})$ & -10 to 10 & 2.63 & 2.67 & 2.71 & 2.75 & 2.74 & 2.78 & 2.80 & 2.73 & 9.14 & \\
\hline$q$ (dimensionless) & $0.1-1.5$ & 0.91 & 0.93 & 0.95 & 0.94 & 0.92 & 0.96 & 0.98 & 0.94 & 5.86 & \\
\hline
\end{tabular}

and velocity vectors. We begin our analysis using 100 particles. After 500 iterations, the best model parameters were reached. The location vectors represent the parameter values. The PSO is attuned with random models and looking for targets by acquainting generations. In every iteration, each model updates its velocity and location utilising the subsequent formulas:

$$
\begin{aligned}
V_{j}^{k+1}= & c_{3} V_{j}^{k}+c_{1} \operatorname{rand}()\left(T_{\text {best }}-P_{j}^{k+1}\right) \\
& +c_{2} \text { rand }\left[\left(J_{\text {best }}-P_{j}^{k+1}\right) P_{j}^{k+1}\right] \\
= & P_{j}^{k}+V_{j}^{k+1}, \\
x_{j}^{k+1}= & x_{j}^{k}+v_{j}^{k+1},
\end{aligned}
$$


where $v_{j}^{k}$ is the $j$ th model velocity at the $k$ th iteration, $P_{j}^{k}$ is the current $j$ th particle location at the $k$ th iteration, rand is the haphazard number amid $[0,1], c_{1}$ and $c_{2}$ are cognitive and social parameters and equal to 2 (Essa and Elhussein $2018 \mathrm{a}, \mathrm{b}), c_{3}$ is the inertial factor that governs the model velocity and its value $<1$ and is very important to maintain the balance between the global and local search and $x_{j}^{k}$ is the particle at the $j$ th location and $k$ th iteration.

\subsection{The parameters estimation}

The preliminary model is progressively established at each iteration step until the best fit can be found among the measured and the predicated data. In each step, the parameters $(A, z, d$ and $q)$ are renewed to catch the best values by minimising the next objective function. The best solution for these parameters obtained through utilising the subsequent objective formula $\left(\varphi_{\mathrm{obj}}\right)$ is

$$
\varphi_{\mathrm{obj}}=\frac{1}{N} \sum_{j=1}^{N}\left[g_{j}^{\mathrm{o}}\left(x_{j}\right)-g_{j}^{\mathrm{p}}\left(x_{j}\right)\right]^{2},
$$

where $N$ is the measured point, $g_{j}^{\mathrm{o}}$ is the measured gravity anomaly and $g_{j}^{\mathrm{p}}$ is the predicted gravity anomaly at a point $\left(x_{j}\right)$. Finally, after the body parameters evaluation $(A, z, d$ and $q)$ of the buried structures, the discrepancy (RMSE) among the measured and predicted gravity anomalies is estimated by taking the square root of equation (8).

\section{Application to theoretical examples}

In this investigation, the benefits of the PSO method were tested by two theoretical anomalies caused by simple models.

\subsection{Model 1}

A gravity anomaly for a sphere model with $K=$ $1000 \mathrm{mGal} \times \mathrm{m}^{2}, z=7 \mathrm{~m}, d=5 \mathrm{~m}, q=1.5$ and profile length $=100 \mathrm{~m}$ has been created utilising equation (2) (figure 1). This anomaly has been processed using the SMA method (equation 4) for $s=$ 2, 3, 4, 5, 6, 7 and $8 \mathrm{~m}$ (figure 2). Next, the PSO method was applied to attain the sphere parameters $(A, z, d$ and $q)$ (table 1$)$. Table 1 confirms the range for each parameter, the estimated parameters result in every $s$-value, the average value $(\phi$ value), the error ( $E$ value) for each parameter and the discrepancy (RMSE) among the measured and the predicted anomalies. The attained results for each parameter $(A, z, d$ and $q)$ are in a suitable and nearby contract among the truly known and evaluated structural parameters.

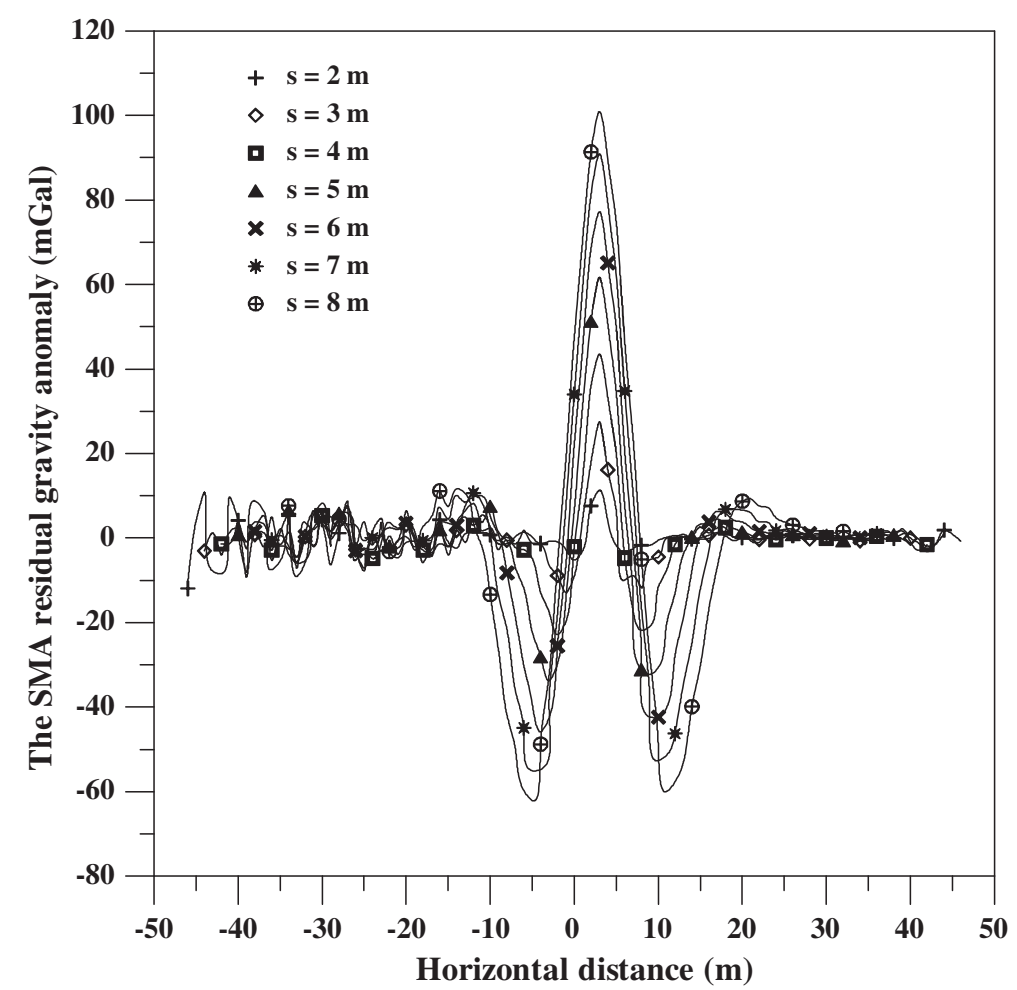

Figure 6. SMA residual gravity anomalies for figure 4 in the case of $10 \%$ noise. 
To check the stability of the method in the existence of noise with the goal to get gravity anomalies closer to the real ones and recognise the robustness of the PSO method, the theoretical example mentioned above was infected by $10 \%$ random noise (figure 1). The SMA residual gravity anomalies for the noisy model using the same $s$-value are presented in figure 3 . The predicted model parameters for the noisy proposed model are revealed in table 1 . In table 1 , the $\phi$ values for $A, z, d$ and $q$ are $986.18 \mathrm{mGal} \times \mathrm{m}^{2}$, $6.71 \mathrm{~m}, 4.76$ and 1.46 and the $E$ values are 1.38 , $4.14,4.41$ and $2.48 \%$, respectively, and the RMSE is $1.72 \mathrm{mGal}$. These values for free noise and the noisy test case for a sphere model indicate that our new PSO method is sound with respect to noise.

\subsection{Model 2}

The PSO method is utilised as a theoretical gravity anomaly influenced by the shallow structure of a horizontal cylinder model with $K=500 \mathrm{mGal}$ $\times \mathrm{m}, z=5 \mathrm{~m}, d=3 \mathrm{~m}, q=1$ and profile length $=100 \mathrm{~m}$ and the effect of a deep structure (regional anomaly) represented by a third-order regional field (figure 4) as

$$
\begin{aligned}
\Delta g\left(x_{j}\right)= & 500 \frac{5}{\left[\left(x_{j}-2\right)^{2}+5^{2}\right]} \\
& +0.0002 x_{j}^{3}+0.002 x_{j}^{2}+x_{j}-40 .
\end{aligned}
$$

After utilising a similar process as mentioned above, the SMA residual gravity anomalies are

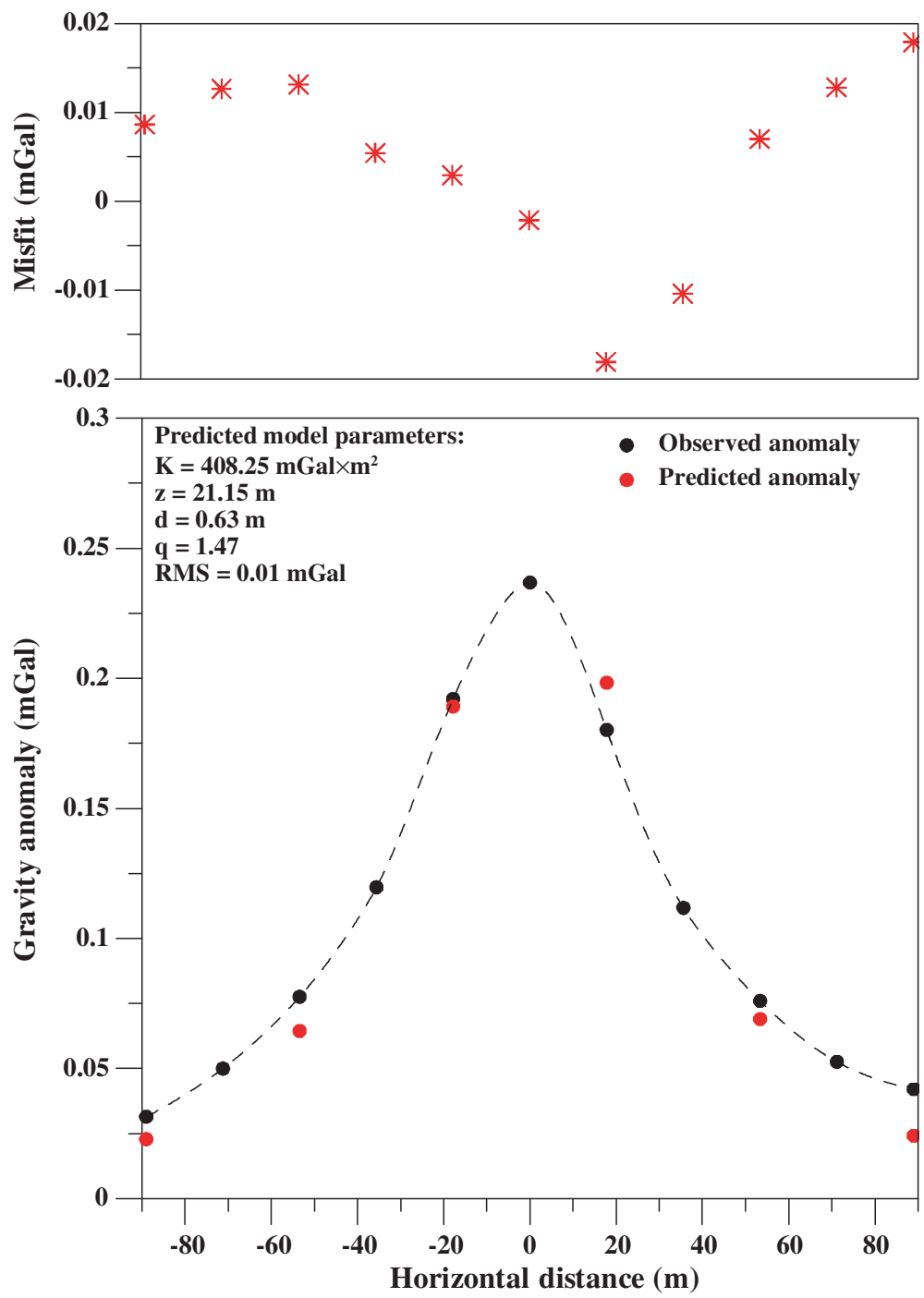

Figure 7. Top panel represents the discrepancy between the observed and the predicted anomaly. The lower panel is the observed and predicted gravity anomaly for the chromite field example, Cuba. 


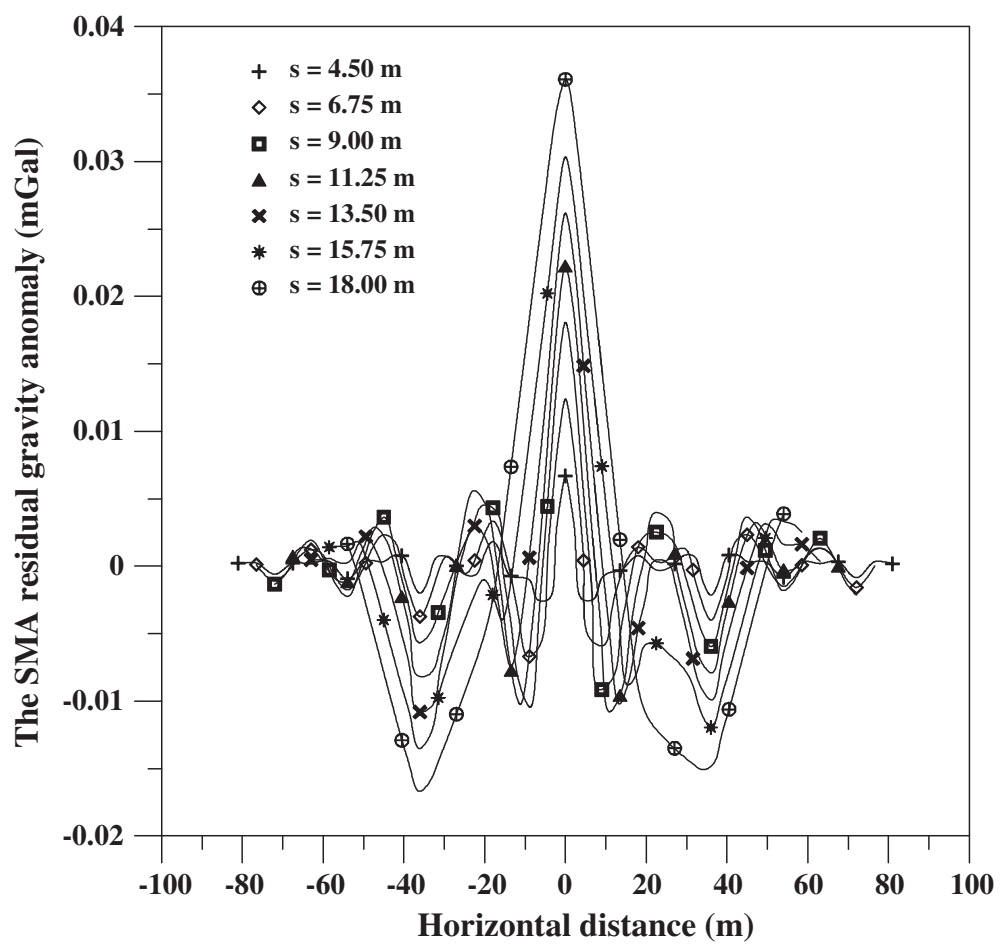

Figure 8. SMA residual gravity anomalies for figure 7.

Table 3. Numerical results for the PSO-method application on the SMA residual gravity data using several s-values for the chromite field example, Cuba.

\begin{tabular}{|c|c|c|c|c|c|c|c|c|c|c|}
\hline \multirow[b]{2}{*}{ Parameters } & \multirow[b]{2}{*}{$\begin{array}{c}\text { Used } \\
\text { ranges }\end{array}$} & \multicolumn{9}{|c|}{ Using the PSO-inversion for the SMA anomalies } \\
\hline & & $\begin{array}{l}s= \\
4.50 \mathrm{~m}\end{array}$ & $\begin{array}{l}s= \\
6.75 \mathrm{~m}\end{array}$ & $\begin{array}{l}s= \\
9 \mathrm{~m}\end{array}$ & $\begin{array}{l}s= \\
11.25 \mathrm{~m}\end{array}$ & $\begin{array}{l}s= \\
13.5 \mathrm{~m}\end{array}$ & $\begin{array}{l}s= \\
15.75 \mathrm{~m}\end{array}$ & $\begin{array}{l}s= \\
18 \mathrm{~m}\end{array}$ & $\phi$-value & $\begin{array}{l}\text { RMS } \\
(\mathrm{mGal})\end{array}$ \\
\hline$A\left(\mathrm{mGal} \times \mathrm{m}^{2}\right)$ & $50-1000$ & 385.12 & 396.40 & 402.93 & 425.24 & 418.56 & 419.47 & 410.04 & 408.25 & 0.01 \\
\hline$z(\mathrm{~m})$ & $1-100$ & 20.10 & 22.30 & 21.54 & 21.24 & 20.87 & 20.93 & 21.05 & 21.15 & \\
\hline$d(\mathrm{~m})$ & -10 to 10 & 0.81 & 0.64 & 0.73 & 0.54 & 0.63 & 0.47 & 0.56 & 0.63 & \\
\hline$q$ (dimensionless) & $0.1-1.7$ & 1.47 & 1.47 & 1.45 & 1.47 & 1.48 & 1.46 & 1.49 & 1.47 & \\
\hline
\end{tabular}

exhibited in figure 5 for several $s$ values $(s=2$, $3,4,5,6,7$ and $8 \mathrm{~m})$. The predicted parameters $(A, z, d$ and $q)$ are tabulated in table 2 which reveal that the $E$ value in the predicted parameters and the RMSE values are zero. This indicates that the SMA method has the capability of eliminating the occurrence of regional anomaly in the measured field until the third-order degree.

We introduced $10 \%$ random noise to the composite gravity anomaly to investigate the viability of this method. For the same $s$ value $(s$ $=2,3,4,5,6,7$ and $8 \mathrm{~m})$, the SMA residual gravity anomalies are accessible in figure 6 . By utilising the PSO method for the noisy data, the results of the body parameters $(A, z, d$ and $q$ ) are offered (table 2). Rendering to the investigation of these results, the $\phi$ values for
$A, z, d$, and $q$ are $482.31 \mathrm{mGal} \times \mathrm{m}, 4.81 \mathrm{~m}$, 2.73 and 0.94 , the $E$ values are $3.54,3.80,9.14$ and $5.86 \%$, respectively, and the RMSE value is $6.17 \mathrm{mGal}$.

These results express that the new PSO method has the efficiency to obtain true parameters with acceptable errors for the measured gravity data even if up to third-order regional effect and noise are found.

\section{Application to field examples}

To inspect and judge the benefits of the implementation of the PSO method, three available mineral exploration real data sets from Cuba, Canada and India were used. The PSO method anticipated inversion of the measured gravity data by simple 
Table 4. A comparative study of the results obtained for the chromite field example, Cuba.

\begin{tabular}{lcccrr}
\hline Parameters & $\begin{array}{c}\text { Drilling } \\
\text { information }\end{array}$ & $\begin{array}{c}\text { Essa (2011) } \\
\text { method }\end{array}$ & $\begin{array}{c}\text { Biswas (2015) } \\
\text { method }\end{array}$ & $\begin{array}{c}\text { Ekinci et al. (2016) } \\
\text { method }\end{array}$ & $\begin{array}{c}\text { The present } \\
\text { method }\end{array}$ \\
\hline$A\left(\mathrm{mGal} \times \mathrm{m}^{2}\right)$ & - & 412.33 & 16.80 & 288.25 & 408.25 \\
$z(\mathrm{~m})$ & 21.00 & 21.02 & 42.30 & 23.23 & 21.15 \\
$d(\mathrm{~m})$ & - & - & -2.40 & 58.73 & 0.63 \\
$q($ dimensionless $)$ & - & 1.5 (estimated) & 1.0 (assumed) & 1.5 (estimated) & 1.47 (estimated) \\
\hline
\end{tabular}
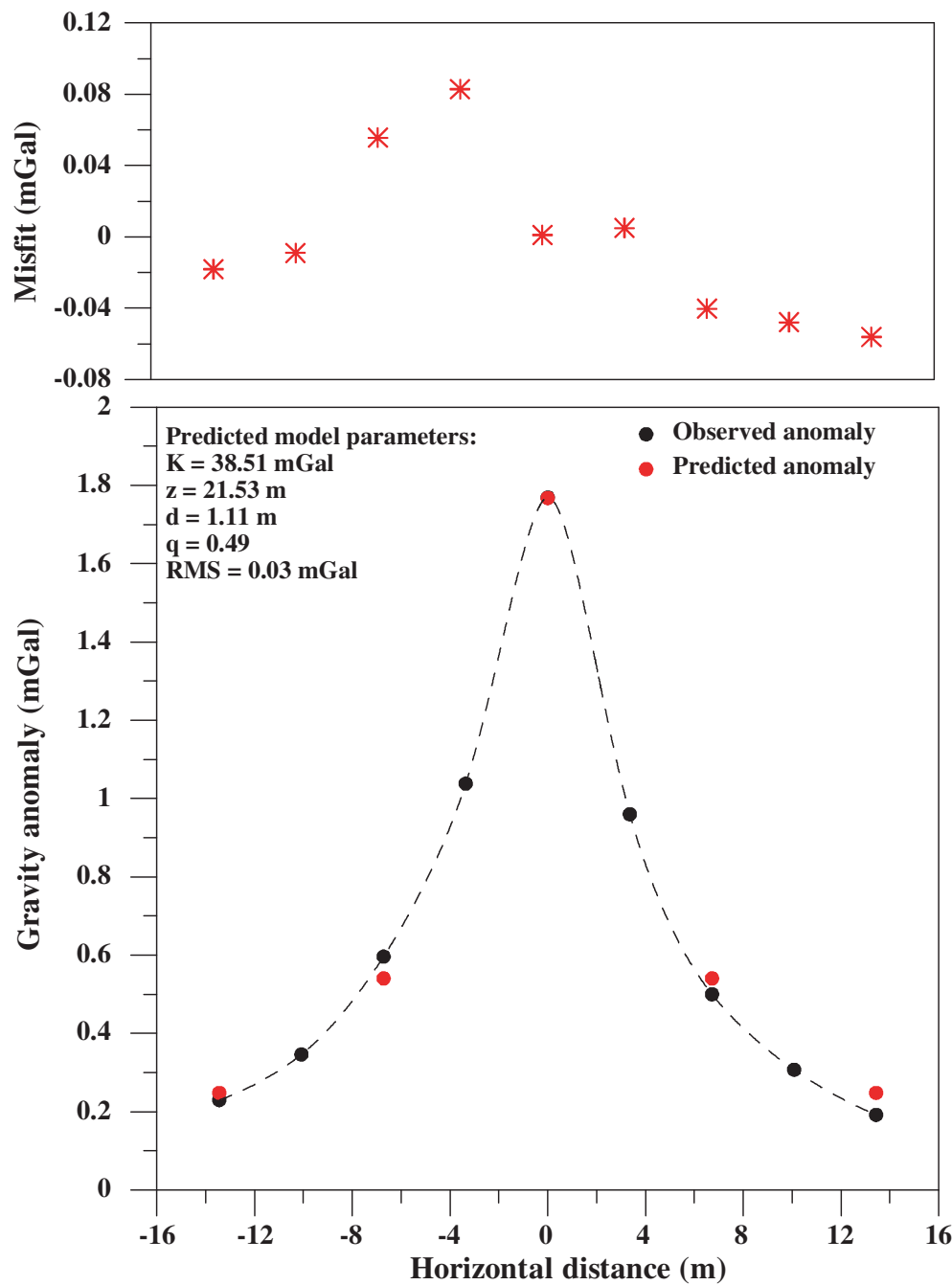

Figure 9. Top panel represents the discrepancy between the observed and the predicted anomaly. The lower panel is the observed and predicted gravity anomaly for the Mobrun sulphide field example, Canada.

models in the limited context of spheres, horizontal cylinders and vertical cylinders. The predicted parameters $(A, z, d$ and $q)$ are elucidated by incorporating with the existing geological information and any further geophysical outcomes.

\subsection{Chromite deposit body}

The chromite region of the Camaguey area, Cuba, was investigated and found that the chromite deposits are in a complex geological environment consisting of serpentinised peridotite and dunite with slight quantities of gabbro, troctolite and anothosite. This complex environment interfered with metamorphic rocks and superimposed by upper cretaceous volcanic rocks with limestone and radiolarian cherts (Davis et al. 1957). Figure 7 shows the residual gravity anomaly over this ore body (Roy 2001) with a length of $180 \mathrm{~m}$. A sample interval of $2.25 \mathrm{~m}$ was utilised to this gravity 


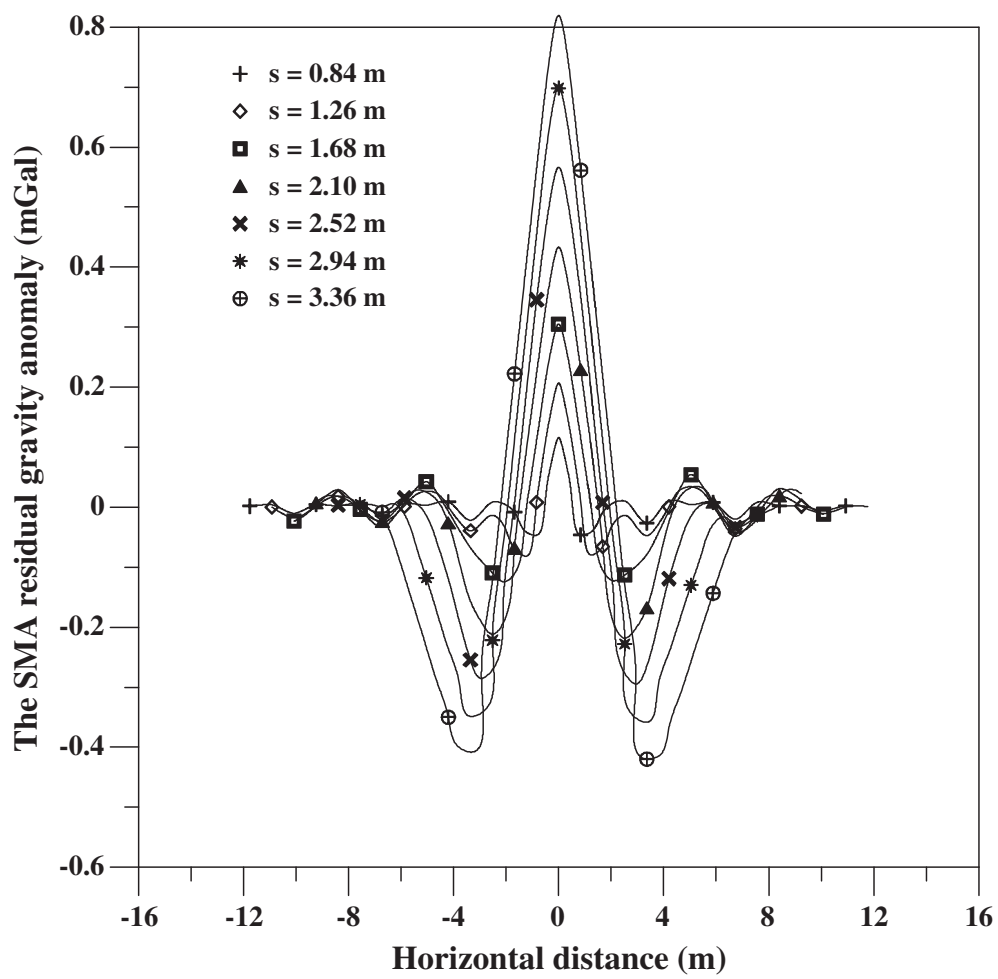

Figure 10. SMA residual gravity anomalies for figure 9.

Table 5. Numerical results for the PSO-method application on the SMA residual gravity data using several s-values for the Mobrun sulphide field example, Canada.

\begin{tabular}{|c|c|c|c|c|c|c|c|c|c|c|}
\hline \multirow[b]{2}{*}{ Parameters } & \multirow[b]{2}{*}{$\begin{array}{l}\text { Used } \\
\text { ranges }\end{array}$} & \multicolumn{9}{|c|}{ Using the PSO-inversion for the SMA anomalies } \\
\hline & & $\begin{array}{c}s= \\
0.84 \mathrm{~m}\end{array}$ & $\begin{array}{c}s= \\
1.26 \mathrm{~m}\end{array}$ & $\begin{array}{c}s= \\
1.68 \mathrm{~m}\end{array}$ & $\begin{array}{c}s= \\
2.10 \mathrm{~m}\end{array}$ & $\begin{array}{c}s= \\
2.52 \mathrm{~m}\end{array}$ & $\begin{array}{c}s= \\
2.94 \mathrm{~m}\end{array}$ & $\begin{array}{c}s= \\
3.36 \mathrm{~m}\end{array}$ & $\phi$-value & $\begin{array}{c}\text { RMS } \\
(\mathrm{mGal})\end{array}$ \\
\hline$A(\mathrm{mGal})$ & $10-500$ & 40.12 & 39.56 & 38.14 & 37.60 & 37.15 & 38.59 & 38.42 & 38.51 & 0.03 \\
\hline$z(\mathrm{~m})$ & $1-100$ & 20.18 & 21.00 & 21.83 & 22.46 & 22.30 & 21.41 & 21.50 & 21.53 & \\
\hline$d(\mathrm{~m})$ & -10 to 10 & 1.21 & 1.17 & 1.15 & 1.02 & 1.14 & 1.03 & 1.05 & 1.11 & \\
\hline$q$ (dimensionless) & $0.1-1.7$ & 0.48 & 0.51 & 0.52 & 0.48 & 0.49 & 0.50 & 0.51 & 0.49 & \\
\hline
\end{tabular}

profile. The interpretation process mentioned above was utilised for this data. For various $s$-values $(s=4.50,6.75,9.00,11.25,13.50,15.75$ and $18.00 \mathrm{~m}$ ), the SMA residual gravity anomalies have been produced (figure 8). The PSO method has been utilised for these anomalies to gauge the parameters $(A, z, d$ and $q$ ) (table 3 ). The inferred results (table 3 ) represent the fitting among the measured and predicted anomaly, i.e., the $\phi$ values for $A, z, d$, and $q$ are $408.25 \mathrm{mGal} \times \mathrm{m}^{2}, 21.15$ $\mathrm{m}, 0.63 \mathrm{~m}$ and 1.47 , respectively, and the RMSE value is $0.01 \mathrm{mGal}$ (figure 7 ). Table 4 shows that the estimated ore body parameters $(A, z, d$ and $q)$, by utilising the present approach, have a reasonable agreement with those obtained from drilling and other inversion techniques (table 4).

\subsection{Mobrun sulphide body}

A base metal huge sulphide ore body has been hosted by volcanic rocks of middle Precambrian age (Grant and West 1965). The residual gravity profile over the massive Mobrun sulphide veins, Noranda, Canada, was studied (Grant and West 1965) (figure 9). This digitised profile was subjected to the SMA method using different $s$-values $(s=0.84,1.26,1.68,2.10,2.52,2.94$ and $3.36 \mathrm{~m}$ ) (figure 10). The PSO method was used to obtain the SMA residual gravity anomalies to appraise the ore parameters $(A, z, d$ and $q)$ (table 5). The $\phi$ values for $A, z, d$ and $q$ are $38.51 \mathrm{mGal}, 21.53 \mathrm{~m}, 1.11 \mathrm{~m}$ and 0.49 , individually, and the RMSE value is $0.03 \mathrm{mGal}$. The 
Table 6. A comparative study of the results obtained for the Mobrun sulphide field example, Canada.

\begin{tabular}{|c|c|c|c|c|c|c|}
\hline \multirow[b]{2}{*}{ Parameters } & \multicolumn{6}{|c|}{ Method } \\
\hline & $\begin{array}{l}\text { Grant and } \\
\text { West (1965) }\end{array}$ & $\begin{array}{l}\text { Roy et al. } \\
\quad(2000)\end{array}$ & $\begin{array}{c}\text { Essa } \\
(2011)\end{array}$ & $\begin{array}{l}\text { Roshan and } \\
\text { Singh (2017) }\end{array}$ & $\begin{array}{l}\text { Ekinci et al. } \\
\qquad(2016)\end{array}$ & $\begin{array}{c}\text { The present } \\
\text { study }\end{array}$ \\
\hline$A(\mathrm{mGal})$ & - & - & 38.13 & 60.00 & 299.11 & 38.51 \\
\hline$z(\mathrm{~m})$ & 30.00 & 29.44 & 21.56 & 30.00 & 35.39 & 21.53 \\
\hline$d(\mathrm{~m})$ & - & - & - & - & 113.93 & 1.11 \\
\hline$q$ (dimensionless) & - & 0.77 (estimated) & 0.5 (estimated) & 0.77 (assumed) & 0.74 (estimated) & 0.49 (estimated) \\
\hline
\end{tabular}
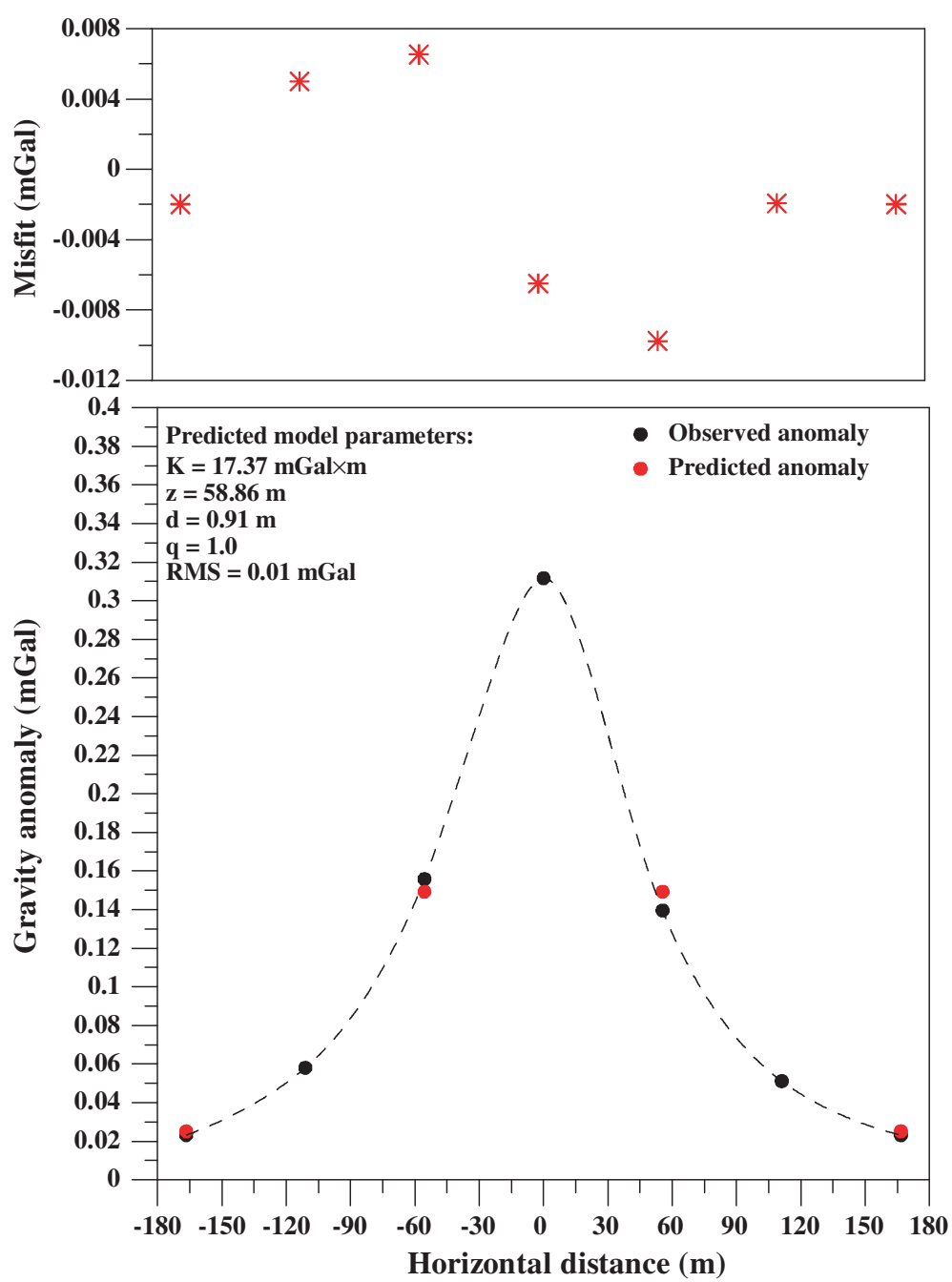

Figure 11. Top panel represents the discrepancy between the observed and the predicted anomaly. The lower panel is the observed and predicted gravity anomaly for the manganese field example, India.

estimated parameters of this source by exploiting the PSO method convolved with the SMA method have a good covenant with the outcomes attained from borehole information and additional inversion approaches (table 6).

\subsection{Manganese ore body}

India is famous for exploring and exporting the largest amount of manganese. A gravity anomaly profile was measured over a manganese ore body, Nagpur, India (Reddi et al. 1995) (figure 11) and has a length of $333 \mathrm{~m}$. The gravity curve was digitised with an interval of $7 \mathrm{~m}$ and subjected to the SMA using various $s$-values $(s=14,21$, $28,35,42,49$ and $56 \mathrm{~m}$ ) (figure 12). The new method was applied to the SMA residual anomalies to determine the source parameters $(A, z, d$ and $q$ ) (table 7 ). The $\phi$ values for $A, z, d$ and $q$ are $17.37 \mathrm{mGal} \times \mathrm{m}, 58.86 \mathrm{~m}, 0.91 \mathrm{~m}$ and 1.00 , 


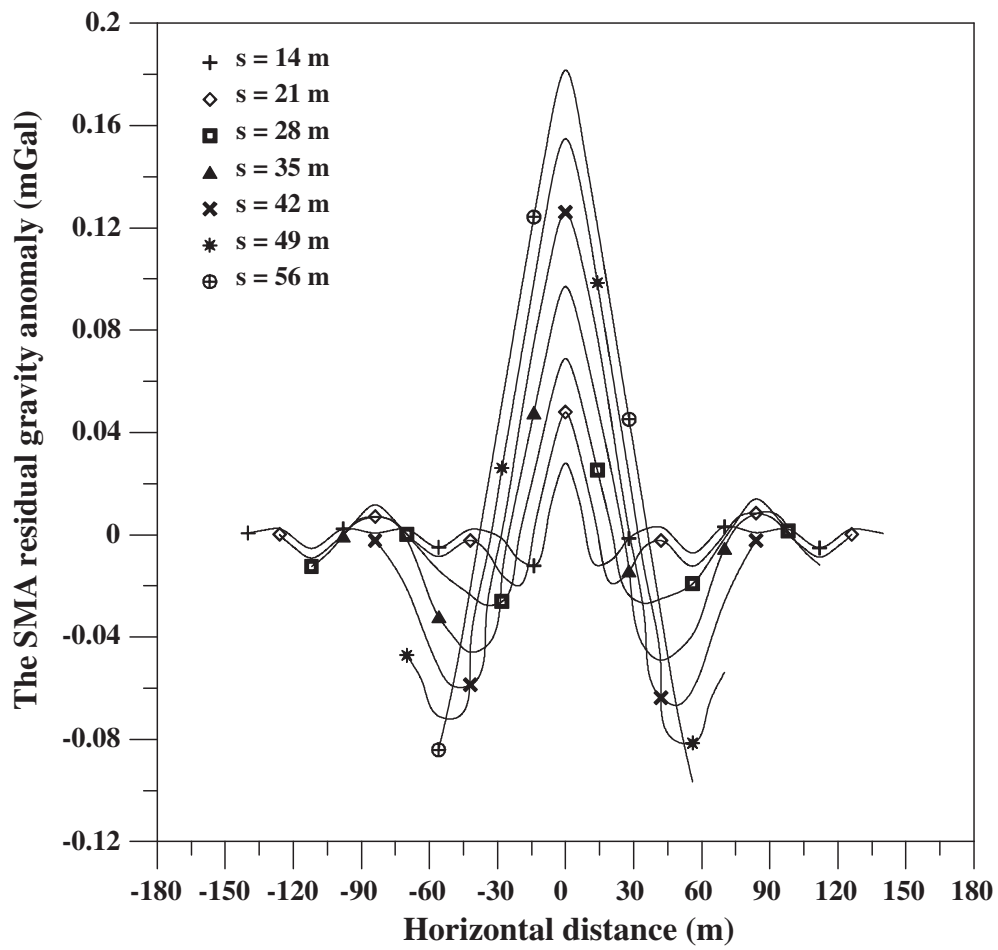

Figure 12. SMA residual gravity anomalies for figure 11.

Table 7. Numerical results for the PSO-method application on the SMA residual gravity data using several s-values for the manganese field example, India.

\begin{tabular}{|c|c|c|c|c|c|c|c|c|c|c|}
\hline \multirow[b]{2}{*}{ Parameters } & \multirow[b]{2}{*}{$\begin{array}{c}\text { Used } \\
\text { ranges }\end{array}$} & \multicolumn{9}{|c|}{ Using the PSO-inversion for the SMA anomalies } \\
\hline & & $\begin{array}{r}s= \\
14 \mathrm{~m}\end{array}$ & $\begin{array}{c}s= \\
21 \mathrm{~m}\end{array}$ & $\begin{array}{c}s= \\
28 \mathrm{~m}\end{array}$ & $\begin{array}{r}s= \\
35 \mathrm{~m}\end{array}$ & $\begin{array}{r}s= \\
42 \mathrm{~m}\end{array}$ & $\begin{array}{r}s= \\
49 \mathrm{~m}\end{array}$ & $\begin{array}{c}s= \\
56 \mathrm{~m}\end{array}$ & $\phi$-value & $\begin{array}{c}\text { RMS } \\
(\mathrm{mGal})\end{array}$ \\
\hline$A(\mathrm{mGal} \times \mathrm{m})$ & $1-100$ & 16.25 & 16.89 & 17.35 & 17.76 & 18.00 & 17.83 & 17.51 & 17.37 & 0.01 \\
\hline$z(\mathrm{~m})$ & $1-100$ & 57.89 & 57.88 & 58.14 & 58.89 & 59.45 & 59.96 & 59.82 & 58.86 & \\
\hline$d(\mathrm{~m})$ & -10 to 10 & 0.89 & 0.91 & 0.93 & 0.93 & 0.88 & 0.91 & 0.90 & 0.91 & \\
\hline$q$ (dimensionless) & $0.1-1.7$ & 0.96 & 0.97 & 1.02 & 1.05 & 1.03 & 1.01 & 1.02 & 1.00 & \\
\hline
\end{tabular}

Table 8. A comparative study of the results obtained for the manganese field example, India.

\begin{tabular}{lcccc}
\hline & \multicolumn{3}{c}{ Method } \\
\cline { 2 - 5 } Parameters & Roy (2001) & Essa (2014) & Ekinci et al. $(2016)$ & The present study \\
\hline$A(\mathrm{mGal} \times \mathrm{m})$ & - & 17.81 & 28.77 & 17.37 \\
$z(\mathrm{~m})$ & 59.80 & 56.78 & 36.08 & 58.86 \\
$d(\mathrm{~m})$ & - & - & 106.77 & 0.91 \\
$q($ dimensionless $)$ & & 1.15 (estimated) & 0.69 (estimated) & 1.00 (estimated) \\
\hline
\end{tabular}

correspondingly, and the RMS value is $0.01 \mathrm{mGal}$. The estimated parameters of the body using the PSO method convolved with the SMA method have a good covenant with the outcomes attained from borehole information and additional inversion approaches (table 8).
Lastly, it is also accentuated that real structures may not have a typical shape (spheres, cylinders, etc.) or structure in the earth. Therefore, the modelling and inversion of real data with the previously mentioned simple structures may not produce the real subsurface buried structures. A minor 
deviation of the real structure from the displayed structure (spheres, cylinders, etc.) can be anticipated to be overlain superimposed of varied sort of noises on the responses characterised by simple and standard geometric structures. Nevertheless, we get a decent gauge of the subsurface structure of a mineralised source and the place and depth of the body. It is additionally featured that the current technique has been applied for the elucidation of gravity data related to mineralisation in Cuba, Canada and India.

\section{Conclusions}

The PSO method is employed for interpreting the SMA residual gravity anomalies utilising various $s$-values. The SMA method has the capability to exterminate up to third-order regional anomaly. This approach exposes all model parameters (amplitude coefficient, depth, location and shape) together and results in a suitable outcome without any doubt in the model parameters. The efficiency of this method has been profitably confirmed, is well known and was established utilising two theoretical tests and three real cases for mineral explorations. Finally, the discrepancy between the measured and the predicted anomalies has been interpreted by evaluating the root mean square error (RMSE) and the predicted parameters for the real cases are found to be in agreement with the other methods in addition to the drilling information. According to these results, the current method will be extended to interpret the magnetic and self-potential anomalies for different mineral exploration sites (future work).

\section{Acknowledgements}

The authors would like to thank Prof N V Chalapathi Rao, Editor-in-Chief, Prof Arkoprovo Biswas, Associate Editor, and the two anonymous expert reviewers for their keen interest and constructive comments for improving our original manuscript. The first author wishes to thank the Science and Technology Development Fund (STDF) and the Institut Francais d'Egypte (IFE) for providing full support to the completion of this work.

\section{References}

Abdelrahman E M and Essa K S 2013 A new approach to semi-infinite thin slab depth determination from second moving average residual gravity anomalies; Explor. Geophys. 44 185-191.

Abdelrahman E M and Essa K S 2015 Three least-squares minimization approaches to interpret gravity data due to dipping faults; Pure Appl. Geophys. 172 427-438.

Abdelrahman E M, El-Araby T M and Essa K S 2003 Shape and depth solutions from third moving average residual gravity anomalies using the window curves method; Kuwait J. Sci. Eng. 30 95-108.

Abdelrahman E M, Abo-Ezz E R, Essa K S, El-Araby T M and Soliman K S 2006 A least-squares variance analysis method for shape and depth estimation from gravity data; J. Geophys. Eng. 3 143-153.

Abdelrahman E M, Essa K S and Abo-Ezz E R 2013 A leastsquares window curves method to interpret gravity data due to dipping faults; J. Geophys. Eng. 10025003.

Al-Garni M A 2008 Walsh transforms for depth determination of a finite vertical cylinder from its residual gravity anomaly; SAGEEP 6-10 689-702.

Amjadi A and Naji J 2013 Application of genetic algorithm optimization and least square method for depth determination from residual gravity anomalies; J. Sci., Eng. Technol. 11 114-123.

Asfahani J and Tlas M 2012 Fair function minimization for direct interpretation of residual gravity anomaly profiles due to spheres and cylinders; Pure Appl. Geophys. 169 $157-165$.

Asfahani J and Tlas M 2015 Estimation of gravity parameters related to simple geometrical structures by developing an approach based on deconvolution and linear optimization techniques; Pure Appl. Geophys. 172 2891-2899.

Babu L A, Reddy K G and Mohan N L 1991 Gravity interpretation of vertical line element and slap - A Mellin transform method; Indian J. Pure Appl. Math. 22 439447.

Biswas A 2015 Interpretation of residual gravity anomaly caused by a simple shaped body using very fast simulated annealing global optimization; Geosci. Front. 6 875-893.

Biswas A 2016 Interpretation of gravity and magnetic anomaly over thin sheet-type structure using very fast simulated annealing global optimization technique; Model Earth Syst. Environ. 230.

Biswas A 2017 A review on modeling, inversion and interpretation of self-potential in mineral exploration and tracing paleo-shear zones; Ore Geol. Rev. 91 21-56.

Chai Y and Hinze W J 1988 Gravity inversion of an interface above which the density contrast varies exponentially with depth; Geophysics 53 837-845.

Davis W E, Jackson W H and Richter D H 1957 Gravity prospecting for chromite deposits in Camaguey province, Cuba; Geophysics 22 848-869.

Eberhart R C and Kennedy J 1995 A new optimizer using particle swarm theory; In: Proceedings of the IEEE - The sixth symposium on Micro Machine and Human Centre, Nagoya, Japan, pp. 39-43.

Ekinci Y L and Yiğitbaş E 2015 Interpretation of gravity anomalies to delineate some structural features of Biga and Gelibolu peninsulas, and their surroundings (northwest Turkey); Geodin. Acta 27 300-319.

Ekinci Y L, Ertekin C and Yiğitbaş E 2013 On The effectiveness of directional derivative based filters on gravity anomalies for source edge approximation: Synthetic 
simulations and a case study from the Aegean Graben System (Western Anatolia, Turkey); J. Geophys. Eng. 10 035005.

Ekinci Y L, Balkaya C, Göktürkler G and Turan S 2016 Model parameter estimations from residual gravity anomalies due to simple-shaped sources using differential evolution algorithm; J. Appl. Geophys. 129 133-147.

Essa K S 2007a A simple formula for shape and depth determination from residual gravity anomalies; Acta Geophys. $55182-190$.

Essa K S 2007b Gravity data interpretation using the s-curves method; J. Geophys. Eng. 4 204-213.

Essa K S 2011 A new algorithm for gravity or self-potential data interpretation; J. Geophys. Eng. 8 434-446.

Essa K S 2012 A fast least-squares method for inverse modeling of gravity anomaly profiles due simple geometricshaped structures; In: Near surface geoscience, 18th European meeting of environmental and engineering geophysics, Paris, France.

Essa K S 2013 Gravity interpretation of dipping faults using the variance analysis method; J. Geophys. Eng. 10 015003.

Essa K S 2014 New fast least-squares algorithm for estimating the best-fitting parameters of some geometricstructures to measured gravity anomalies; J. Adv. Res. 5 57-65.

Essa K S and Elhussein M 2018a PSO (particle swarm optimization) for interpretation of magnetic anomalies caused by simple geometrical structures; Pure Appl. Geophys. $1753539-3553$.

Essa K S and Elhussein M 2018b Gravity data interpretation using new algorithms: A comparative study; In: Gravity-geoscience applications (ed.) Zouaghi Z, Industrial Technology and Quantum Aspect, InTech, Croatia, $226 \mathrm{p}$.

Essa K S, Nady A G, Mostafa M S and Elhussein M 2018 Implementation of potential field data to depict the structural lineaments of the Sinai Peninsula, Egypt; J. Afr. Earth Sci. 147 43-53.

Grant F S and West G F 1965 Interpretation theory in applied geophysics; McGraw-Hill Book Company, New York, 583p.

Griffin W R 1949 Residual gravity in theory and practice; Geophysics 14 39-58.

Gupta O P 1983 A least-squares approach to depth determination from gravity data; Geophysics 48 360-375.

Hajihassani M, Jahed Armaghani D and Kalatehjari R 2018 Applications of particle swarm optimization in geotechnical engineering: A comprehensive review; Geotech. Geol. Eng. 36 705-722.

He Q and Wang L 2007 An effective co-evolutionary particle swarm optimization for constrained engineering design problems; Eng. Appl. Artif. Intell. 20 89-99.

Hinze W J, von Frese R R B and Saad A H 2013 Gravity and magnetic exploration: Principles, practices and applications; Cambridge University Press, UK, 512p.

Jordehi A R 2018 Enhanced leader particle swarm optimisation (ELPSO): An efficient algorithm for parameter estimation of photovoltaic (PV) cells and modules; Sol. Energy 159 78-87.

Kawada Y and Kasaya T 2018 Self-potential mapping using an autonomous underwater vehicle for the Sunrise deposit,
Izu-Ogasawara arc, southern Japan; Earth Planet. Space 70142.

Kilty K T 1983 Werner deconvolution of profile potential field data; Geophysics 48 234-237.

Luu K, Noble M, Gesret A, Belayouni N and Roux P 2018 A parallel competitive particle swarm optimization for nonlinear first arrival travel-time tomography and uncertainty quantification; Comput. Geosci. 113 81-93.

Mehanee S A 2014 Accurate and efficient regularised inversion approach for the isolated gravity anomalies; Pure Appl. Geophys. 171 1897-1937.

Mehanee S A 2015 Tracing of paleo-shear zones by selfpotential data inversion: Case studies from the KTB, Rittsteig, and Grossensees graphite-bearing fault planes; Earth Planet. Space 67 14-47.

Mehanee S A and Essa K S 2015 2.5D regularized inversion for the interpretation of residual gravity data by a dipping thin sheet: Numerical examples and case studies with an insight on sensitivity and non-uniqueness; Earth Planet. Space 67130.

Nishijma J and Naritomi J 2017 Interpretation of gravity data to delineate underground structure in the Beppu geothermal field, central Kyushu, Japan, regional studies; J. Hydrol. 11 84-95.

Osman O, Albora A M and Ucan O N 2006 A new approach for residual gravity anomaly profile interpretations: Forced neural network (FNN); Ann. Geophys. 49 1201-1208.

Pawlowski R S 1994 Green's equivalent-layer concept in gravity bandpass filter design; Geophysics 59 69-76.

Rao P, Subrahmanyan M and Murthy S 1986 Nomograms for direct interpretation of magnetic anomalies due to long horizontal cylinders; Geophysics 51 2150-2159.

Reddi A G B, Murthy B S R and Kesavanani M A 1995 Compendium of four decades of geophysical activity in geological survey of India; GSI Special Publication No. 36, Geological Survey of India.

Roshan R and Singh U K 2017 Inversion of residual gravity anomalies using tuned PSO; Geosci. Instrum. Method Data Syst. 6 71-79.

Roy L 2001 Short note: Source geometry identification by simultaneous use of structural index and shape factor; Geophys. Prospect. 49 159-164.

Roy L, Agarwal B N P and Shaw R K 2000 A new concept in Euler deconvolution of isolated gravity anomalies; Geophys. Prospect. 48 559-575.

Santilano A, Godio A and Manzella A 2018 Particle swarm optimization for simultaneous analysis of magnetotelluric and time-domain electromagnetic data; Geophysics $\mathbf{8 3}$ E151-E159.

Singh A and Biswas A 2016 Application of global particle swarm optimization for inversion of residual gravity anomalies over geological bodies with idealized geometries; Nat. Resour. Res. $25297-$ 314.

Stavrev P Y 1997 Euler deconvolution using differential similarity transformations of gravity or magnetic anomalies; Geophys. Prospect. 45 207-246.

Sundararajan N and Rama Brahmam G 1998 Spectral analysis of gravity anomalies caused by slab-like structures: A Hartley transform technique; J. Appl. Geophys. 39 53-61. 
Wang Y, Lv J, Zhu L and Ma Y 2010 Crystal structure prediction via particle-swarm optimization; Phys. Rev. B82 094116 .

Corresponding editor: Arkoprovo Biswas
Zhang J, Zhong B, Zhou X and Dai Y 2001 Gravity anomalies of $2 \mathrm{D}$ bodies with variable density contrast; Geophysics 66 809-813. 